\title{
Weight Stigmatization among Physical Therapy Students and Registered Physical Therapists
}

\author{
Michal Elboim-Gabyzon ${ }^{a} \quad K^{2}$ arin Attar ${ }^{a} \quad$ Smadar Peleg ${ }^{b}$ \\ a Faculty of Social Welfare and Health Sciences, Physical Therapy Department, University of \\ Haifa, Haifa, Israel; b Physical Therapy Department, Zefat Academic College, Zefat, Israel
}

\section{Keywords}

Weight stigma - Obesity · Physical therapy · Students · Assessment

\begin{abstract}
Introduction: Weight stigmatization is reflected in anti-fat attitudes and stereotypical perceptions of people who are overweight; it has been demonstrated to be prevalent in many segments of society across multiple countries. Studies examining the prevalence of weight stigmatization use different research tools, which can hinder inter-study comparisons. There is also evidence indicating weight stigmatization among registered physical therapists, although its magnitude differs between studies. Limited information exists regarding the attitudes and beliefs of physical therapy (PT) students toward individuals with obesity. Examining weight stigmatization among PT students is particularly important for developing appropriate educational interventions that may influence the professional lives of future physical therapists. Objective: This study aims to characterize and compare the stigmatizing attitudes and beliefs of PT students and certified physical therapists regarding people with obesity in Israel. Its secondary objective is to translate three weight stigmatization questionnaires into Hebrew and determine their psychometric properties. Methods: A cross-sectional, anonymous, and computerized self-report survey was completed by 285 certified physical therapists (average age $39.6 \pm 10.1$ years) and 115 PT students (average age $26.4 \pm 4.9$ years). The study used three validated weight stigma questionnaires employed in earlier studies to determine different aspects of weight stigmatization: the Fat Phobia Scale (short form; FPS), Anti-Fat Attitudes (AFA) questionnaire, and Beliefs about Obese People (BAOP). These questionnaires were translated into Hebrew and their psychometric properties ascertained. $R \boldsymbol{e}$ sults: Similar to the original English versions, the translated versions of the three question-
\end{abstract}


Elboim-Gabyzon et al.: Weight Stigmatization among PT Students and Physical Therapists

naires demonstrated good internal consistency (Cronbach's $\alpha$ values of FPS $=0.77$; AFA $=0.75$; $B O A P=0.59$ ). The three questionnaires showed a low correlation. No significant difference was noted in the FPS and AFA scores between groups, reflecting that both demonstrated average weight stigmatization (FBS in both groups: average score of 3.6 out of 5; AFA therapists: $3.3 \pm 1.2$, students: $3.0 \pm 1.2$ out of 9). However, significant between-group differences were observed for BOAP, which examines beliefs regarding individuals' control over their weight (therapists: $16.4 \pm 5.6$, students: $18.0 \pm 5.7$ out of $48 ; p<0.01$ ). Conclusion: Student and certified physical therapists demonstrate average levels of weight stigmatization, as reflected in the FPS and AFA scores. Nevertheless, compared to certified physical therapists, physical therapist students believe more strongly that obesity cannot be controlled by the individual. The students' beliefs could affect their clinical judgment and behavior as health care professionals in the future. Therefore, anti-fat attitudes and stereotypical perceptions should be addressed and remediated early using educational interventions during the study period.

(C) 2020 The Author(s)

Published by S. Karger AG, Basel

\section{Introduction}

Today, obesity is considered a worldwide epidemic spreading to all segments of society [1]. Numerous studies have documented the weight stigmatization of people with obesity, which is reflected in the stereotypical perceptions of these people as having negative characteristics, such as laziness, lack of self-discipline, absence of willpower, and lack of motivation to change $[2,3]$. Such biased and discriminative behaviors are prevalent in multiple life domains, including education, employment, interpersonal relationships, and health care facilities [4]. Paradoxically, the increase in the number of people with obesity in society has not resulted in a reduction in the stigmatization of and discrimination against individuals with obesity [4].

Often, health care professionals are required to treat individuals who are overweight for their primary condition of obesity [5] and their comorbidities and obesity-related chronic diseases, such as chronic respiratory disease, stroke, coronary heart disease, diabetes mellitus, and degenerative joint disease [6]. However, numerous studies have documented that health care professionals (e.g., physicians, nurses, dietitians, and psychologists) are often prejudiced against people with obesity and maintain negative attitudes and beliefs regarding them $[7,8]$. Such prejudices may influence these professionals' decisions on patient care, often reducing the effectiveness of obesity prevention efforts and leading to destructive consequences in terms of the psychological and physical well-being of individuals with obesity [9].

Physical therapists are among the health professionals who provide weight management counseling by offering appropriate fitness programs and also treat the impairments and disabilities resulting from overweight-related comorbidities (e.g., stroke and arthritis) [10]. Some unique characteristics of the physical therapy (PT) profession could potentially affect weight stigmatization among its practitioners [11-13]. First, PT treatment often involves exposing different body parts of the patient, which may be considered unaesthetic by the therapist. Furthermore, PT treatment often requires close physical contact with the client. For example, multipletreatment approaches involve manipulating soft tissues (e.g., conducting massages) or joints (e.g., practicing joint mobilization exercises and techniques) [12, 13]. Moreover, the rehabilitation process, which includes assisting and supporting the client during activities such as standing and walking, often requires therapists to exert physical effort. These factors may increase the physical therapists' antagonism toward individuals with obesity, resulting in discriminating behaviors.

A systematic review conducted by Cavaleri et al. [14] summarized six studies, specifically focusing on the prevalence of explicit weight stigmatization among physical therapists [8, 
Elboim-Gabyzon et al.: Weight Stigmatization among PT Students and Physical Therapists

15-19]. Setchell et al. [12], who focused on the patients' perspective, conducted face-to-face interviews with 15 Australian PT patients, which were followed by telephonic interviews 2 weeks later. All the patients believed that PT settings posed negative (or stigmatizing) experiences for patients who were overweight, since body weight is emphasized during treatments, particularly while body parts are being exposed. Furthermore, some patients reported that some of the therapists negatively judged their weight. In contrast, the other studies focused on the explicit attitudes and beliefs of physical therapists toward individuals with obesity $[8,11,13,16,17]$. By utilizing the Anti-Fat Attitudes (AFA) questionnaire and some case studies, Setchell et al. [17] demonstrated explicit and implicit weight stigmatization among 265 Australian physical therapists. Sack et al. [16] claimed that American physical therapists $(n=345)$ have neutral attitudes toward people with obesity. However, an examination of specific items revealed that "approximately half of the respondents described people with obesity as lazy, unattractive, noncompliant, and weak willed power" (p. 812) [16]. In addition, the physical therapists believed that obesity is mainly caused by environmental and behavioral factors, such as a lack of physical activity and poor nutritional habits, rather than genetic and metabolic causes [16]. However, the questionnaire used in the latter study [16] was not appropriately validated. Wise et al. [8] used the Fat Phobia Scale (FPS) to examine attitudes toward patients with obesity by questioning 221 subjects who were being treated by 13 types of rehabilitation health professionals in Australia. The study sample included 41 physical therapists (19\% of the total sample), who demonstrated average levels of negative attitudes toward individuals with obesity (mean 3.7 out of $5 \pm 0.42$ ). In summary, weight stigmatization among physical therapists has been examined in only major Western countries (the USA, Australia, and Canada) [14], and each has utilized different research tools [20, 21]. These studies provide evidence regarding the dominance of weight stigmatization among physical therapists. However, the magnitude of this phenomenon is probably related to the measurement tool used in the research as well as differences in nationality and culture. Accordingly, there is a need to explore weight stigmatization within this context.

Moreover, earlier studies mainly focused on certified physical therapists but largely ignored the attitudes of PT students. By understanding the attitudes of PT students, we can develop educational approaches and interventions to curtail the negative implications of weight stigmatization among future health care professionals. To our knowledge, only one study has examined PT students' attitudes and knowledge regarding obesity [15]. This study examined 170 full-time students from a South African university. It used a structured, selfadministered questionnaire adopted from the Obesity Risk Knowledge and Fat Phobia Scale. The mean FPS score was 3.95 (out of 5, with a standard deviation [SD] of 0.6), which reflected a negative attitude [22].

The current study aims to translate three validated weight stigma questionnaires to Hebrew and ascertain the psychometric properties of the translated versions to examine the phenomenon in a different cultural context. In addition, the study characterizes and compares the stigmatizing attitudes and beliefs of PT students and certified physical therapists regarding people with obesity.

\section{Materials and Methods}

Study Design

The study comprised two parts: (1) the translation of three validated questionnaires on different aspects of weight stigmatization according to accepted forward and backward translation guidelines from English to Hebrew [23], and (2) a survey of certified physical therapists and PT students that utilized the translated questionnaires. 
Elboim-Gabyzon et al.: Weight Stigmatization among PT Students and Physical Therapists

Table 1. Participant demographic characteristics

\begin{tabular}{lccc}
\hline & PT students $(n=115)$ & $\begin{array}{c}\text { Certified physical } \\
\text { therapists }(n=285)\end{array}$ & $p$ value \\
\hline Age, years & $26 \pm 4.9(19-55)^{\mathrm{a}}$ & $39.6 \pm 10.1(26-69)^{\mathrm{c}}$ & $<0.0001$ \\
Male/Female & $45(39.8) / 68(60.2)^{\mathrm{a}}$ & $59(21) / 223(79)^{\mathrm{e}}$ & - \\
Height, cm & $169.2 \pm 9.0(150-194)^{\mathrm{a}}$ & $167.4 \pm 8.8(150-202)^{\mathrm{c}}$ & 0.07 \\
Weight, kg & $66.1 \pm 13.2(45-106)^{\mathrm{b}}$ & $67.3 \pm 14.3(45-140)^{\mathrm{d}}$ & 0.47 \\
BMI & $23 \pm 3.2(16.4-31.1)^{\mathrm{b}}$ & $24 \pm 4.0(17.4-45.2)^{\mathrm{d}}$ & 0.03 \\
Work experience, years & - & $12.4 \pm 10.3(0-41)^{\mathrm{e}}$ & \\
\hline
\end{tabular}

Data are presented as the mean \pm SD (range) or $n(\%)$. Statistical significance: $p<0.05$. PT, physical therapy; BMI, body mass index.

${ }^{\mathrm{a}} n=112 .{ }^{\mathrm{b}} n=111 .{ }^{\mathrm{c}} n=284 .{ }^{\mathrm{d}} n=283 .{ }^{\mathrm{e}} n=282$.

\section{Translation Process}

Three bilingual physical therapists independently translated the three questionnaires from English to Hebrew. The final Hebrew versions were obtained after a group discussion among the translators and the study coordinator. The next stage involved the backward translation of questionnaires into English; this was independently performed by three professional translators who had not participated in the previous steps. The final Hebrew and original English versions of the three questionnaires were presented to five bilingual (native Hebrew speaking) qualified physical therapists, who ascertained that the questions were accurate and understandable. The panel agreed that all the questionnaire items met these criteria. The Hebrew versions can be obtained from the authors.

\section{Survey Administration}

An anonymous, computerized self-report survey was designed using the Form-Logix and the University of Haifa computer interface. In the survey, the three translated questionnaires appeared in a fixed order. The survey included a sociodemographic questionnaire requesting information on the age, gender, education, occupational data, and height and weight (for body mass index calculations) of the participants (see Table 1). All the data were automatically and immediately stored in the Form Logix software, and participant anonymity was maintained.

To recruit PT students, we sent emails to all the PT students of two of the five academic institutions in Israel offering a PT degree (i.e., University of Haifa and Zefat Academic College). Certified PT professionals were recruited through snowball sampling by contacting the administrators of private and public PT clinics and by addressing professional interest groups in media networks (e.g., Facebook). The addressing email included an explanation on the survey's nature and objectives, a declaration specifying a participant's right to refuse or discontinue filling out the questionnaires at any time, and a statement that the completion of the survey indicates informed consent to participate in the study.

\section{Instruments}

Three commonly used assessment tools were chosen to examine different aspects of weight stigmatization and increase the validity of the survey.

FPS Short Form

The FPS was developed by Bacon et al. [24] in the USA to assess negative and fat-phobic attitudes toward individuals with obesity. It comprises 14 items based on the original 
Elboim-Gabyzon et al.: Weight Stigmatization among PT Students and Physical Therapists

50-item scale developed by Robinson et al. [25]. The FPS focuses on three common negative features related to people with obesity: lack of self-discipline, inactivity, and unattractiveness. Accordingly, it includes 14 pairs of opposite adjectives that might describe people with obesity, such as lazy-industrious, active-inactive, and low self-esteem-high self-esteem. For each item pair, the participant is asked to mark the position on a Likert scale from 1 to 5 that best describes people with obesity. Scoring is performed in accordance with the instructions outlined by the developers, with higher scores indicating more negative attitudes toward people with obesity and greater fat phobias [24]. A high internal consistency was reported for the FPS (Cronbach's $\alpha=0.87-0.91$ ) [24, 25]. A score of 3.6 represents average fat phobia, whereas scores of 4.4 or more represent high levels of fat phobia [25]. Furthermore, the FPS was translated to other languages, such as Spanish, Turkish, and German $[22,26,27]$.

AFA Questionnaire

The AFA includes 13 weight-related statements developed by Crandall [28] on three domains, each representing a different aspect of explicit anti-fat attitudes: (1) "Dislike" prejudice toward people with obesity (7 items; e.g., "I really do not like fat people that much"); (2) "Fear of Fat," which refers to an individual's concerns about becoming fat, rather than prejudice toward people who are overweight (3 items), and (3) "Willpower," which is one's belief in the controllability of weight ( 3 items; e.g., "Fat people tend to be fat pretty much through their own fault") [28]. Items are rated on a Likert scale ranging from 0 to 9 ( $0=$ very strongly disagree; 9 = very strongly agree). The total score for the AFA and scores for each of the three domains were calculated. Scores higher than zero indicate weight stigmatization, with higher scores indicating stronger anti-fat attitudes [28]. Furthermore, the three parts of the questionnaire were reported to have good internal consistency (Cronbach's $\alpha$ of the Dislike part $=0.84-0.86$; that of Fear of Fat $=0.79-0.88$; and that of Willpower $=0.66-0.80$ ) [28]. The AFA was translated from English into several languages, including Polish, Turkish, and Spanish [29].

\section{Beliefs about Obese People}

The BAOP tool assesses an individual's beliefs regarding the cause of obesity, including the belief that obesity is controllable (e.g., item number 5: "Most obese people eat more than non-obese people" [30]). The tool is composed of 8 items, which are assessed on a 6-point scale (ranging from -3 , I strongly disagree, to +3 , I strongly agree), with scores ranging between 0 and 48 . Higher scores indicate a stronger belief that obesity is not under the control of the person with obesity. The tool developers reported a high internal consistency (Cronbach's $\alpha=0.83$ ] [30]. Responses were scored in the present study according to the instructions outlined by the developers [30]. The BAOP was translated from English to other languages, such as Turkish [31], and Spanish [32].

\section{Statistical Analysis}

Descriptive data included means and SDs, counts, and percentages, as appropriate. Internal consistency was determined by Cronbach's $\alpha$ coefficient and item-total correlations. $\alpha$ values $\geq 0.9$ were considered excellent; $0.7 \leq \alpha<0.9$ was considered good, $0.6 \leq \alpha<0.7$ was considered acceptable, $0.5 \leq \alpha<0.6$ was considered poor, and $<0.5$ was considered unacceptable [33].

Items were analyzed by calculating the indexes of "alpha if item deleted" and "corrected item-total correlation" to examine the structural coherence of the scale. In accordance with the recommendation of Ferketich [34], values of corrected item-total correlations should range from 0.30 to 0.70 for a good instrument. 
Table 2. Internal consistency of the Hebrew versions of the questionnaires

\begin{tabular}{lll}
\hline Questionnaire/items, $n$ & $\begin{array}{l}\text { Corrected item- } \\
\text { total correlation }\end{array}$ & $\begin{array}{l}\text { Alpha } \\
\text { (if item is deleted) }\end{array}$ \\
\hline FPS & & \\
1 & 0.27 & 0.76 \\
2 & 0.36 & 0.76 \\
3 & 0.44 & 0.75 \\
4 & 0.39 & 0.75 \\
5 & 0.46 & 0.74 \\
6 & 0.47 & 0.74 \\
7 & 0.52 & 0.74 \\
8 & 0.28 & 0.76 \\
9 & 0.22 & 0.77 \\
10 & 0.27 & 0.76 \\
11 & 0.40 & 0.75 \\
12 & 0.35 & 0.76 \\
13 & 0.42 & 0.75 \\
14 & 0.45 & 0.75 \\
\hline
\end{tabular}

Cronbach's $\alpha$ coefficient of FPS scale equal to 0.77 .

\begin{tabular}{ccc}
\hline$A F A$ & & \\
1 & 0.47 & 0.73 \\
2 & 0.21 & 0.75 \\
3 & 0.37 & 0.74 \\
4 & 0.35 & 0.74 \\
5 & 0.48 & 0.72 \\
6 & 0.53 & 0.72 \\
7 & 0.47 & 0.73 \\
8 & 0.37 & 0.74 \\
9 & 0.35 & 0.74 \\
10 & 0.32 & 0.74 \\
11 & 0.23 & 0.75 \\
12 & 0.35 & 0.74 \\
13 & 0.40 & 0.74
\end{tabular}

Cronbach's $\alpha$ coefficient of AFA scale equal to 0.75 .

\begin{tabular}{lcc}
\hline BAOP & 0.19 & 0.59 \\
1 & 0.16 & 0.60 \\
2 & 0.53 & 0.48 \\
3 & 0.26 & 0.57 \\
4 & 0.42 & 0.52 \\
5 & 0.60 & 0.45 \\
6 & -0.06 & $0.65^{\mathrm{a}}$ \\
7 & 0.31 & 0.55 \\
8 & Cronbach's $\alpha$ coefficient of BAOP scale equal to 0.59. \\
\multicolumn{2}{l}{ a Note that deleting item 7 raises the $\alpha$ coefficient value to 0.65. } \\
\multicolumn{3}{c}{ FPS, Fat Phobia Scale (short form); AFA, Anti-Fat Attitudes; BAOP, } \\
\multicolumn{2}{c}{ Beliefs about Obese People. }
\end{tabular}

Pearson's correlation was used to compare the three questionnaires. Pearson's correlation coefficients higher than 0.75 denote a strong correlation, whereas values ranging from 0.50 to 0.75 suggest a moderate correlation [35]. Furthermore, due to the sampling distribution, the Wilcoxon score rank (rank sums) was conducted to compare the scores of the three questionnaires (FPS, AFA, and BAOP) between student and certified PTs (two separate groups). In each group, the gender difference was examined as well. Significance was set at 
Elboim-Gabyzon et al.: Weight Stigmatization among PT Students and Physical Therapists

Table 3. Results of the correlation values between the questionnaires (Pearson's analysis scores and $p$ value)

\begin{tabular}{lcccccc}
\hline & FPS & \multicolumn{2}{c}{ AFA } & & BAOP \\
\cline { 2 - 5 } & & AFA total & $\begin{array}{l}\text { Dislike } \\
\text { subscale }\end{array}$ & $\begin{array}{l}\text { Fear of Fat } \\
\text { subscale }\end{array}$ & $\begin{array}{l}\text { Willpower } \\
\text { subscale }\end{array}$ & \\
\hline FPS & - & 0.24 & 0.15 & 0.15 & 0.22 & -0.27 \\
& & $<0.001$ & 0.0024 & 0.0020 & $<0.001$ & $<0.001$ \\
\hline AFA total & 0.24 & - & 0.75 & 0.7 & 0.66 & -0.39 \\
& $<0.001$ & & $<0.001$ & $<0.001$ & $<0.001$ & $<0.001$ \\
\hline Dislike subscale & 0.15 & 0.75 & - & 0.19 & 0.28 & -0.19 \\
& 0.002 & $<0.001$ & & 0.0020 & $<0.001$ & 0.001 \\
\hline Fear of Fat subscale & 0.15 & 0.70 & 0.19 & - & 0.25 & -0.25 \\
& 0.002 & $<0.001$ & 0.002 & & 0.0020 & $<0.001$ \\
\hline Willpower subscale & 0.22 & 0.66 & 0.28 & 0.25 & - & -0.41 \\
& $<0.001$ & $<0.001$ & $<0.001$ & $<0.001$ & & $<0.001$ \\
\hline BAOP & -0.27 & -0.39 & -0.19 & -0.25 & -0.41 & -
\end{tabular}

FPS, Fat Phobia Scale (short form); AFA, Anti-Fat Attitudes; BAOP, Beliefs about Obese People.

$p \leq 0.05$, and statistical analyses were performed using JMP Analysis Software (SAS Institute Inc., Cary, NC, USA).

\section{Results}

The study sample included 285 certified physical therapists (average age $39.6 \pm 10.1$ years) and 115 PT students (average age $26.4 \pm 4.9$ years). Table 1 depicts the demographic characteristics of each group.

Psychometric Proprieties of the Hebrew Versions of the Questionnaires

Good internal consistency was demonstrated for the FPS and AFA questionnaires, with Cronbach's $\alpha$ values of 0.77 and 0.75 , respectively. Further analysis deleting each item supported the retention of all items (Table 2). In addition, the internal consistency of the BOAP questionnaire was acceptable (Cronbach's $\alpha=0.59$ ). Item number 7, "Obesity is rarely caused by a lack of willpower" [30], was found to have a negative effect on the internal consistency, since the deletion of this item increased Cronbach's $\alpha$ value to 0.65 (Table 2).

A significant low positive correlation was found between AFA and FPS scores $(r=0.24$, $p<0.0001$ ), as shown in Table 3. As indicated by Table 3, the BOAP score demonstrated a significant low negative correlation with the total and subscale AFA scores and with the FPS scores ( $r=-0.19$ to $0.41, p \leq 0.0001$ ).

\section{Weight Stigmatization among PT Students and among Certified Physical Therapists}

Table 4 presents the scores of the three weight stigma questionnaires for PT students and certified physical therapists. The mean score of the PT students in the FPS was $3.6 \pm 0.4$ out of 5, which is considered as an average level of fat phobia [24]. The students' score in the AFA was $3.0 \pm 1.2$ out of 9 , indicating negative attitudes toward people with obesity [28]. The 
Elboim-Gabyzon et al.: Weight Stigmatization among PT Students and Physical Therapists

Table 4. Comparison between the three questionnaires' results for PT students as well as certified physical therapists

\begin{tabular}{lccc}
\hline Group & PT students $(n=115)$ & $\begin{array}{l}\text { Certified physical } \\
\text { therapists }(n=285)\end{array}$ & $p$ value \\
\hline $\begin{array}{l}\text { Questionnaire (score range) } \\
\text { FPS (1-5) }\end{array}$ & $3.6 \pm 0.4(2.5-4.57)$ & $3.6 \pm 0.5(2.1-5.6)$ & 0.21 \\
AFA total (0-9) & $3.0 \pm 1.2(0-5.85)^{\mathrm{a}}$ & $3.3 \pm 1.2(0.7-7.2)^{\mathrm{c}}$ & 0.06 \\
\hline AFA subscale & $1.5 \pm 1.1(0-5)^{\mathrm{b}}$ & $1.7 \pm 1.3(0-7.7)^{\mathrm{e}}$ & 0.05 \\
Dislike (0-9) & $4.5 \pm 2.8(0-9)^{\mathrm{b}}$ & $4.5 \pm 2.5(0-9)^{\mathrm{d}}$ & 0.92 \\
Fear of Fat (0-9) & $5.3 \pm 2.1(0-9)^{\mathrm{a}}$ & $5.6 \pm 1.9(0-9)^{\mathrm{c}}$ & 0.12 \\
Willpower (0-9) & $18.0 \pm 5.7(7-37)^{\mathrm{b}}$ & $16.4 \pm 5.6(5-48)^{\mathrm{d}}$ & 0.009 \\
BAOP (0-48) &
\end{tabular}

Data are presented as the mean \pm SD (range). PT, physical therapy; FPS, Fat Phobia Scale (short form); AFA, Anti-Fat Attitudes; BAOP, Beliefs about Obese People.

${ }^{\mathrm{a}} n=284 .{ }^{\mathrm{b}} n=283 .{ }^{\mathrm{c}} n=114 .{ }^{\mathrm{d}} n=113 .{ }^{\mathrm{e}} n=111$.

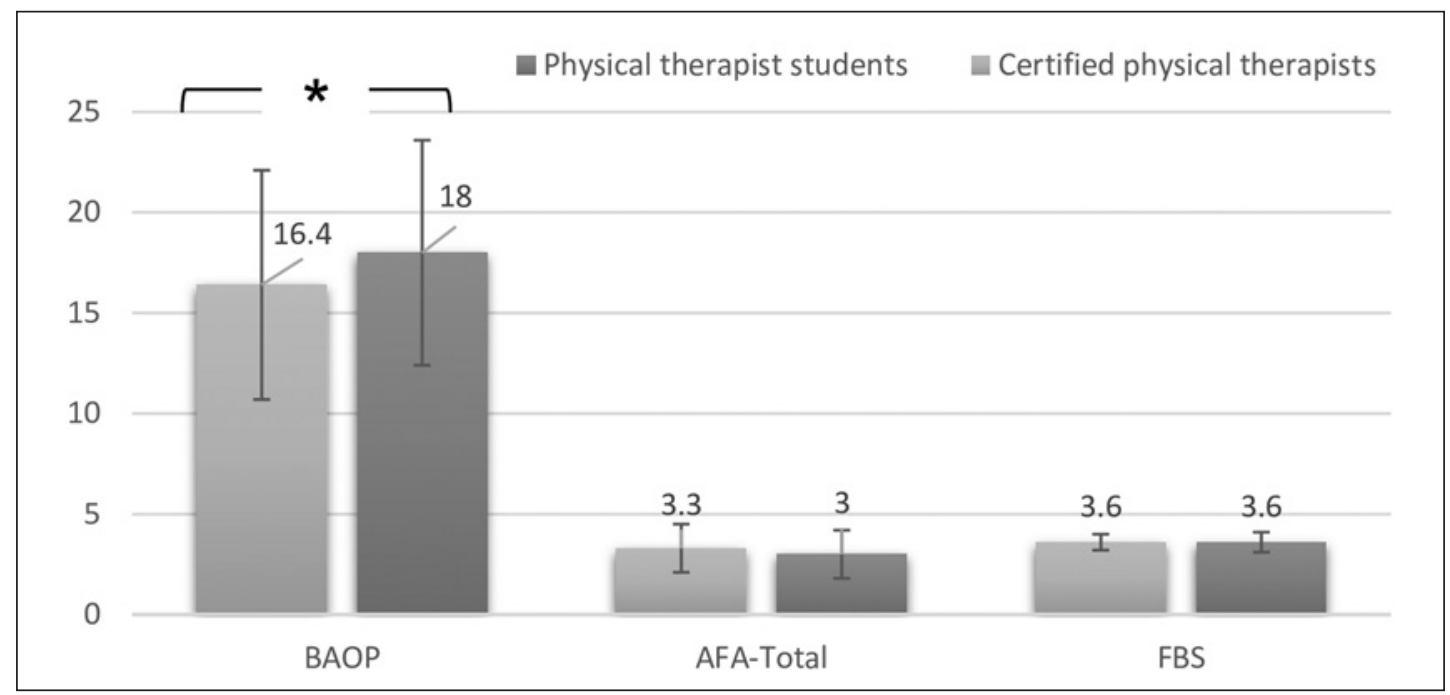

Fig. 1. Comparison among the three questionnaires' results for PT students as well as certified physical therapists (mean \pm SD).

highest subtotal scores of the AFA were recorded for Willpower and Fear of Fat. PT students scored $18.0 \pm 5.7$ out of 48 on the BOAP scale.

With regard to the FPS, certified physical therapists demonstrated an average level of fat phobia ( $3.6 \pm 0.5$ out of 5 ). The total AFA score was $3.3 \pm 1.2$ out of 9 . The highest scores were recorded for Willpower and Fear of Fat. The mean \pm SD of the BOAP score was $16.4 \pm 5.6$ out of 48 .

\section{Comparison in Weight Stigmatization between PT Students and Certified Physical}

Therapists

In terms of FPS, there were no inter-group differences, and both demonstrated an average level of fat phobia [24] (Fig. 1). Additionally, there were no significant inter-group differences in the total and subscales of AFA scores, thus indicating that both groups have a negative attitude toward people with obesity. In both groups, the highest scores were recorded for 
Elboim-Gabyzon et al:: Weight Stigmatization among PT Students and Physical Therapists

Table 5. Comparison between the three questionnaires' results by gender in each group

\begin{tabular}{|c|c|c|c|c|c|c|}
\hline & \multicolumn{3}{|c|}{ PT students $(n=115)$} & \multicolumn{3}{|c|}{ Certified physical therapists $(n=285)$} \\
\hline & $\begin{array}{l}\text { men } \\
(n=45)\end{array}$ & $\begin{array}{l}\text { women } \\
(n=68)\end{array}$ & $p$ value & $\begin{array}{l}\text { men } \\
(n=59)\end{array}$ & $\begin{array}{l}\text { women } \\
(n=223)\end{array}$ & $p$ value \\
\hline \multicolumn{7}{|l|}{ Questionnaire } \\
\hline FPS (1-5) & $3.5 \pm 0.4$ & $3.7 \pm 0.4$ & 0.11 & $3.7 \pm 0.4$ & $3.6 \pm 0.5$ & 0.59 \\
\hline AFA total (0-9) & $2.8 \pm 1.2$ & $3.3 \pm 1.1$ & 0.039 & $2.9 \pm 1.1$ & $3.4 \pm 1.2$ & 0.005 \\
\hline \multicolumn{7}{|l|}{ AFA subscale } \\
\hline Dislike (0-9) & $1.4 \pm 1.2$ & $1.5 \pm 1.0$ & 0.66 & $1.4 \pm 1.1$ & $1.8 \pm 1.3$ & 0.048 \\
\hline Fear of Fat $(0-9)$ & $3.6 \pm 2.6$ & $5.3 \pm 2.6$ & $<0.001$ & $3.7 \pm 2.5$ & $4.8 \pm 2.5$ & 0.002 \\
\hline Willpower (0-9) & $5.3 \pm 2.2$ & $5.4 \pm 1.8$ & 0.73 & $5.5 \pm 1.9$ & $5.7 \pm 1.9$ & 0.46 \\
\hline BAOP $(0-48)$ & $18.3 \pm 6.4$ & $17.6 \pm 5.1$ & 0.50 & $18.0 \pm 6.3$ & $15.9 \pm 5.3$ & 0.013 \\
\hline
\end{tabular}

Data are presented as the mean \pm SD. PT, physical therapy; FPS, Fat Phobia Scale (short form); AFA, Anti-Fat Attitudes; BAOP, Beliefs about Obese People.

Willpower and Fear of Fat, while the lowest scores were observed on the Dislike subscale. This indicates that both groups believe that people with obesity have low willpower. However, the participants have a relatively low level of dislike for people with obesity and are concerned about gaining weight themselves.

A significant difference between the two groups was found in the results of the BAOP questionnaire (Fig. 1). PT students had significantly higher scores than certified physical therapists (students: $18.0 \pm 5.7$; therapists: $16.4 \pm 5.6$ out of $48 ; p<0.01$ ), indicating that students have a stronger belief that obesity is not under the individual's control.

\section{Difference between Genders in Weight Stigma}

Table 5 presents the results for each gender per study group. The FPS scores did not show significant gender differences between the two groups. However, the AFA total scores were significantly different in terms of gender in both groups, demonstrating a higher negative attitude of women compared to men toward people with obesity. In both the groups, women demonstrated significantly higher scores for fears of becoming fat (subscale of AFA) compared to men. The BAOP scores were not different in terms of gender in the student group. In contrast, in the physical therapist group, the BAOP scores were significantly higher in men compared to women, indicating that men more strongly believed that obesity is not under the individual's control.

\section{Discussion}

The current study had two aims. First, we ascertained the psychometric properties of the translated Hebrew versions of three known and validated weight stigma questionnaires (FPS, AFA, and BOAP). Second, we characterized and compared the stigmatizing attitudes and beliefs of PT students and certified physical therapists regarding people with obesity.

The results demonstrated a significant low correlation between the results of the three questionnaires. This is consistent with the results of previous studies [21] and may be because weight stigmatization is a broad and complex concept that encompasses three aspects: stereotype, prejudice, and discrimination [36]. Each of the questionnaires addressed different dimensions of weight stigmatization. However, in some of the tools, the underlying theo- 
Elboim-Gabyzon et al.: Weight Stigmatization among PT Students and Physical Therapists

retical concepts and the exact definition of these concepts were lacking or undefined [37]. For example, the AFA includes three diverse subcategories: (a) "Dislike" or prejudice toward people with obesity; (b) "Fear of Fat," which refers to the questionnaire participant's selfconcern regarding his/her own weight gain risk (note that the title of this subcategory implies that it focuses on the individual with obesity), and (c) "Willpower," the belief in the controllability of weight gain [28]. On the other hand, BOAP focused only on one dimension: the individual's beliefs regarding the causes of obesity including beliefs regarding the degree of control and responsibility individuals have over their own weight [30]. While our study demonstrated a low correlation between the total AFA score and BOAP, which was contrary to our expectations, a previous study also demonstrated a low correlation between AFA's "Willpower subcategory" and BOAP [21]. This example emphasizes the importance of clearly defining the specific dimensions of weight stigma in the context of professional health care [37].

The Cronbach's $\alpha$ analysis of the FBS $(\alpha=0.76)$ yielded results similar to previously reported results (0.82 [38] or 0.81 [4]). However, slightly lower values were reported by the developer of the tool (0.87-0.91) [24]. Similarly, the analysis of the AFA questionnaire demonstrated good Cronbach's $\alpha$ values in conformance with the values reported by the developer [28] of the tool. The BOAP questionnaire demonstrated the lowest psychometric features with only acceptable internal consistency (Cronbach's $\alpha=0.59$ ). Further analysis revealed that deleting one item that was not sufficiently clear in the translated version (item number 7: "Obesity is rarely caused by a lack of willpower") increased the Cronbach's $\alpha$ score to 0.66 ; this was identical to the value reported by Swift et al. [39], which was used for assessing weight bias among UK-based trainee health care professionals. However, our values were lower than those reported by the BOAP scale's developer, whose $\alpha$ scores were $0.65-0.82$ [30]. In summary, with the exception of item 7 in the BOAP, all three translated questionnaires demonstrated satisfactory internal consistency [33].

The current study aimed to characterize and compare weight stigmatization levels among PT students and certified physical therapists. PT students demonstrated an average level of fat phobia and negative attitudes toward people with obesity. To the best of our knowledge, only one pervious study focused on PT students [15]. Awotidebe and Phillips [15] examined 170 students from a university in Western Cape, South Africa, using the following tools: FBS and the Obesity Risk Knowledge (ORK-10) scale. Only the results of FBS could be compared with our study. The results of the FBS in the study by Awotidebe and Phillips [15] was $3.95 \pm$ 0.6 , which was similar to our results $(3.6 \pm 0.4)$. However, it should be noted that the two student samples were different not only in terms of nationality, but also in age and study level (their sample included both undergraduate and postgraduate students). The results of both studies involving PT students were consistent with findings regarding students in other health professions $[39,40]$.

Certified physical therapists demonstrated average levels of fat phobia in the FPS [24]; this was consistent with previous results from research on certified physical therapists in Australia (3.7 \pm 0.42 ) [8] and other health care professionals [39-43]. Certified physical therapists demonstrated negative attitudes toward individuals with obesity, as reflected in the total and subscales of the AFA. These results are consistent with a previous report on AFA scores made by Australian physical therapists (3.2 \pm 1.1 ) [4].

This current result, which indicates the existence of overall similar stigmatizing attitudes among PT students and certified physical therapists, suggests that the present PT curriculum in Israel has had no significant positive effect on the students' attitudes regarding obesity. Nevertheless, the BOAP scores indicated that PT students differed significantly from certified physical therapists in one respect: they demonstrated stronger beliefs that obesity is not under a person's control. These results cannot be compared to previous studies, as none of 
Elboim-Gabyzon et al.: Weight Stigmatization among PT Students and Physical Therapists

those studies utilized this scale for assessing PT professionals. It should be noted that, being aware that not all aspects of obesity are under the control of the individual, as demonstrated by the PT students in the current study, does not necessarily mean that students have more positive attitudes toward individuals with obesity [44, 45]. Awareness of the fact that the individual may be unable to control some aspects of obesity may even reduce the professional's motivation to treat the patient. In fact, a previous study revealed that BOAP does not differentiate between knowledge and attitude [46]. Therefore, future studies should clarify how health care providers' motivation to treat individuals with obesity without bias is affected by the belief that obesity cannot be necessarily controlled by the individual.

Another important point that should be noted is that, despite the widespread use of BOAP and the AFA, the BOAP scale has not established a definition for high, medium, or low levels of belief to date. Similarly, negative attitude levels, measured by the AFA, are not well defined. According to the developer of the AFA tool, any score higher than zero indicates some weight stigmatizing attitudes, with higher scores indicating stronger anti-fat attitudes [28]. These points should be addressed in future research $[4,28]$. The current study's findings point out that weight stigmatization is frequent among Israel's PT students and physical therapists. This finding matches international findings regarding weight stigmatization attitudes among physical therapists. Therefore, it is necessary to raise awareness regarding this phenomenon and design national action plans for reducing weight stigmatization, its associated possible biases, and discrimination in clinical settings. The action plans should include educational interventions that involve PT professional organizations, higher education institutes, and the health care system. These programs should be specifically aimed at the PT practitioners [13]. Furthermore, within PT/health care settings, regulations should be enforced [47] in order to create physical environments that are suitable for individuals with obesity. Such environments should include appropriately sized equipment and attire (e.g., beds, wheelchairs, appropriate gowns, etc.), which may diminish the perception of stigmatization [48]. Additionally, creating a friendly environment can facilitate the treatment of patients with excess weight, thereby avoiding provoking emotions such as disgust, contempt, or anger in the health providers. The necessity of reducing these emotions is based on understanding one important fact - chiefly, that emotions have a fundamental role in promoting stereotypes and prejudices [49]. The three major emotions that were found to be related to weight stigmatization and prejudice toward people with excess weight gain are disgust, contempt, or anger $[50,51]$.

Finally, this study had some limitations. Although the questionnaires were anonymously completed, desirability bias may have affected the results. In addition, since the questionnaires were distributed through the Internet, we could not calculate the compliance percentage. Furthermore, no golden standard is recognized in this field; this limited the validity of the three instruments used in this study. Further studies are required in order to clarify how weight-stigmatizing attitudes among PT students and certified physical therapists affect their actual interactions with patients with obesity, and the effect of such interactions on treatment quality.

\section{Statement of Ethics}

The study was approved by the Ethical Review Boards of the University of Haifa and Zefat Academic College. The addressing email included an explanation on the survey's nature and objectives, a declaration specifying a participant's right to refuse or discontinue filling out the questionnaires at any time, and a statement that the completion of the survey indicates informed consent to participate in the study. 
Elboim-Gabyzon et al.: Weight Stigmatization among PT Students and Physical Therapists

\section{Disclosure Statement}

The authors have no conflicts of interest to declare.

\section{Funding Sources}

There were no sources of funding for this study.

\section{Author Contributions}

M.E.G., K.A.P., and S.P. substantially contributed to the study conception, design, and to the interpretation of data, were involved in critically revising the manuscript, and in data collection. K.A.P. was the study coordinator. M.E.G. was responsible for data analysis and the preliminary writing of the manuscript. All authors read and approved the final draft of the paper.

\section{References}

1 Tsujimoto T, Kajio H, Sugiyama T. Obesity, diabetes, and length of time in the United States: Analysis of National Health and Nutrition Examination Survey 1999 to 2012. Medicine (Baltimore). 2016 Aug;95(35):e4578.

2 Dhurandhar NV. Obesity stigma: a persistent problem, a possible solution. Int J Obes. 2013 Nov; 37(11): 1413-4.

3 Puhl RM, Brownell KD. Psychosocial origins of obesity stigma: toward changing a powerful and pervasive bias. Obes Rev. 2003 Nov;4(4):213-27.

4 Puhl RM, Heuer CA. The stigma of obesity: a review and update. Obesity (Silver Spring). 2009 May;17(5): 941-64.

5 Engin A. The definition and prevalence of obesity and metabolic syndrome. Adv Exp Med Biol. 2017;960:1-17.

6 Heymsfield SB, Wadden TA. Mechanisms, pathophysiology, and management of obesity. N Engl J Med. 2017 Jan;376(3):254-66.

7 Puhl R, Suh Y. Health consequences of weight stigma: implications for obesity prevention and treatment. Curr Obes Rep. 2015 Jun;4(2):182-90.

8 Wise FM, Harris DW, Olver JH. Attitudes to obesity among rehabilitation health professionals in Australia. J Allied Health. 2014 Aug;43(3):162-8.

9 Langdon J, Rukavina P, Greenleaf C. Predictors of obesity bias among exercise science students. Adv Physiol Educ. 2016 Jun;40(2):157-64.

10 Unger RH, Orci L. Diseases of liporegulation: new perspective on obesity and related disorders. FASEB J. 2001 Feb;15(2):312-21.

11 Setchell J, Gard M, Jones L, Watson BM. Addressing weight stigma in physiotherapy: development of a theorydriven approach to (re)thinking weight-related interactions. Physiother Theory Pract. 2017 Aug;33(8):597610.

12 Setchell J, Watson B, Jones L, Gard M. Weight stigma in physiotherapy practice: patient perceptions of interactions with physiotherapists. Man Ther. 2015 Dec;20(6):835-41.

13 Setchell J, Watson BM, Gard M, Jones L. Physical Therapists' Ways of Talking About Overweight and Obesity: clinical Implications. Phys Ther. 2016 Jun;96(6):865-75.

14 Cavaleri R, Short T, Karunaratne S, Chipchase LS. Weight stigmatisation in physiotherapy: a systematic review. Phys Ther Rev. 2016;21(1):1-9.

15 Awotidebe A, Phillips J. Knowledge and attitudes of physiotherapy students towards obesity. S Afr J Physiother. 2009;65(3):27-31.

16 Sack S, Radler DR, Mairella KK, Touger-Decker R, Khan H. Physical therapists' attitudes, knowledge, and practice approaches regarding people who are obese. Phys Ther. 2009 Aug;89(8):804-15.

17 Setchell J, Watson B, Jones L, Gard M, Briffa K. Physiotherapists demonstrate weight stigma: a cross-sectional survey of Australian physiotherapists. J Physiother. 2014 Sep;60(3):157-62.

18 Snodgrass SJ, Carter AE, Guest M, Collins CE, James C, Kable AK, et al. Weight management including dietary and physical activity advice provided by Australian physiotherapists: a pilot cross-sectional survey. Physiother Theory Pract. 2014 Aug;30(6):409-20.

19 You L, Sadler G, Majumdar S, Burnett D, Evans C. Physiotherapists' perceptions of their role in the rehabilitation management of individuals with obesity. Physiother Can. 2012;64(2):168-75. 
Elboim-Gabyzon et al.: Weight Stigmatization among PT Students and Physical Therapists

20 Swami V, Monk R. Weight bias against women in a university acceptance scenario. J Gen Psychol. 2013 Jan-Mar; 140(1):45-56.

21 Swami V, Pietschnig J, Stieger S, Tovée MJ, Voracek M. An investigation of weight bias against women and its associations with individual difference factors. Body Image. 2010 Jun;7(3):194-9.

22 Stein J, Luppa M, Ruzanska U, Sikorski C, König HH, Riedel-Heller SG. Measuring negative attitudes towards overweight and obesity in the German population - psychometric properties and reference values for the German short version of the Fat Phobia Scale (FPS). PLoS One. 2014 Dec;9(12):e114641.

23 Guillemin F, Bombardier C, Beaton D. Cross-cultural adaptation of health-related quality of life measures: literature review and proposed guidelines. J Clin Epidemiol. 1993 Dec;46(12):1417-32.

24 Bacon JG, Scheltema KE, Robinson BE. Fat phobia scale revisited: the short form. Int J Obes Relat Metab Disord. $2001 \mathrm{Feb} ; 25(2): 252-7$.

25 Robinson BE, Bacon JG, O’Reilly J. Fat phobia: measuring, understanding, and changing anti-fat attitudes. Int J Eat Disord. 1993 Dec;14(4):467-80.

26 Hayran O, Akan H, Özkan AD, Kocaoglu B. Fat phobia of university students: attitudes toward obesity. J Allied Health. 2013;42(3):147-50.

27 Olsen LK, De La Cruz AP, Duvall A, Phromsid N, Amatya A. Fat phobias held by high school students in Mexico and Thailand. Res Q Exercise Sport. 2014;85(S1):A83.

28 Crandall CS. Prejudice against fat people: ideology and self-interest. J Pers Soc Psychol. 1994 May;66(5):88294.

29 Crandall CS, D'Anello S, Sakalli N, Lazarus E, Nejtardt GW, Feather NT. An attribution-value model of prejudice: anti-fat attitudes in six nations. Pers Soc Psychol Bull. 2001;27(1):30-7.

30 Allison DB, Basile VC, Yuker HE. The measurement of attitudes toward and beliefs about obese persons. Int J Eating Disord. 1991;10(5):599-607.

31 Dedeli O, Bursalioglu SA, Deveci A. Validity and reliability of the Turkish version of the attitudes toward obese persons scale and the beliefs about obese persons scale. Clin Nurs Stud. 2014;2(4):105.

32 Magallares A. Well-being and prejudice toward obese people in women at risk to develop eating disorders. Span J Psychol. 2012 Nov;15(3):1293-302.

33 Bland JM, Altman DG. Cronbach's alpha. BMJ. 1997 Feb;314(7080):572.

34 Ferketich S. Focus on psychometrics. Aspects of item analysis. Res Nurs Health. 1991 Apr;14(2):165-8.

35 Portney L, Watkins MP. Foundations of clinical research: Applications to practice. 2nd ed. Upper Saddle River: Prentice Hall Health; 2002. p. 34.

36 Link BG, Phelan JC. Conceptualizing stigma. Annu Rev Sociol. 2001;27(1):363-85.

37 Lacroix E, Alberga A, Russell-Mathew S, McLaren L, von Ranson K. Weight Bias: A Systematic Review of Characteristics and Psychometric Properties of Self-Report Questionnaires. Obes Facts. 2017;10(3):223-37.

38 Poon MY, Tarrant M. Obesity: attitudes of undergraduate student nurses and registered nurses. J Clin Nurs. 2009 Aug;18(16):2355-65.

39 Swift JA, Hanlon S, El-Redy L, Puhl RM, Glazebrook C. Weight bias among UK trainee dietitians, doctors, nurses and nutritionists. J Hum Nutr Diet. 2013 Aug;26(4):395-402.

40 Berryman DE, Dubale GM, Manchester DS, Mittelstaedt R. Dietetics students possess negative attitudes toward obesity similar to nondietetics students. J Am Diet Assoc. 2006 Oct;106(10):1678-82.

41 Foster GD, Wadden TA, Makris AP, Davidson D, Sanderson RS, Allison DB, et al. Primary care physicians' attitudes about obesity and its treatment. Obes Res. 2003 Oct;11(10):1168-77.

42 Puhl RM, Latner JD, King KM, Luedicke J. Weight bias among professionals treating eating disorders: attitudes about treatment and perceived patient outcomes. Int J Eat Disord. 2014 Jan;47(1):65-75.

43 Sikorski C, Luppa M, Glaesmer H, Brähler E, König HH, Riedel-Heller SG. Attitudes of health care professionals towards female obese patients. Obes Facts. 2013;6(6):512-22.

44 O'Brien KS, Puhl RM, Latner JD, Mir AS, Hunter JA. Reducing anti-fat prejudice in preservice health students: a randomized trial. Obesity (Silver Spring). 2010 Nov;18(11):2138-44.

45 Poustchi Y, Saks NS, Piasecki AK, Hahn KA, Ferrante JM. Brief intervention effective in reducing weight bias in medical students. Fam Med. 2013 May;45(5):345-8.

46 Ip EH, Marshall S, Vitolins M, Crandall SJ, Davis S, Miller D, et al. Measuring medical student attitudes and beliefs regarding patients who are obese. Acad Med. 2013 Feb;88(2):282-9.

47 Pearl RL. Weight bias and stigma: public health implications and structural solutions. Soc Issues Policy Rev. 2018;12(1):146-82.

48 Budd GM, Mariotti M, Graff D, Falkenstein K. Health care professionals' attitudes about obesity: an integrative review. Appl Nurs Res. 2011 Aug;24(3):127-37.

49 Dovidio JF, Brigham JC, Johnson BT, Gaertner SL. Stereotyping, prejudice, and discrimination: Another look. In: Macrae CN, Stangor C, Hewstone M, editors. Stereotypes and stereotyping. New York: Guildford Press; 1996. pp. 276-319.

50 Vartanian LR, Trewartha T, Vanman EJ. Disgust predicts prejudice and discrimination toward individuals with obesity. J Appl Soc Psychol. 2016;46(6):369-75.

51 Vartanian LR, Thomas MA, Vanman EJ. Disgust, contempt, and anger and the stereotypes of obese people. Eat Weight Disord. 2013 Dec;18(4):377-82. 